\title{
Canudos: organização, poder e o processo de institucionalização de um modelo de governança comunitária*
}

\author{
Canudos: Organization, Power and the Institutionalization Process of a \\ Communitarian Governance Model
}

Paulo Emilio Matos Martins ${ }^{1}$

\section{Resumo}

Antônio Conselheiro e seus seguidores protagonizaram no semi-árido sertanejo do Bello Monte (Bahia, 1893-97) um curioso empreendimento comunitário que alcançou o expressivo crescimento populacional de $10335 \%$ em apenas quatro anos de existência e que resistiu, por quase 10 meses, às investidas de cerca da metade do efetivo da força terrestre brasileira de então. Não é razoável imaginar que semelhante feito tenha prescindido de um sistema de organização e governo minimamente eficaz, malgrado seu trágico destino. Neste artigo, esse sistema organizacional é analisado com base em três dimensões - a econômica, a política e a religiosa - e no processo de institucionalização das formas de organização e governança locais que as mesmas inspiraram. A partir de uma leitura semiológica dos referentes organizacionais do universo conselheirista e do cotejo das três fontes utilizadas na pesquisa - os depoimentos dos descendentes dos sobreviventes do episódio, os relatos dos cronistas-testemunhas do fato e a historiografia sobre a temática -, as conclusões da pesquisa apontam no sentido de que Canudos teria sido um grande mutirão, cuja liderança assumiu uma forma a qual identificamos como a do "coronel com o sinal trocado" ou de um "coronel pelo avesso", parodiando a imagem euclidiana de Antônio Conselheiro.

Palavras-chave: Administração Brasileira; Movimentos sociais; Canudos; Institucionalismo.

\section{Abstract}

Antônio Conselheiro and its followers had perform in the Brazilian backlands (1893-1897) a curious communitarian experience that reached 10,335\% growth in its population, in only four years, and resisted, during ten months, to the onslaughts of almost the half of the Brazilian army. It is not reasonable to imagine that it has done without an efficient governance and organization, despite its tragic end. In this assay we analyze this organization based on a institutionalization model of three dimensions: the economic, the politic and the religious ones, and in its governance and local organization. Based on a semiotic reading of the descendants of the Canudos survivors discourse; the reports of the witness-chroniclers of the episode and the historiography of the fact, my conclusions point out that Canudos (the Bello Monte of Antônio Conselheiro) would have been a great "mutirão" (mutual aid), whose its leadership assumed a form which I identify as the symmetric of the "coronelismo" (colonel style, in the Victor Nunes Leal meaning) or "um coronel pelo avesso" (a contrary colonel), making a parody with the Euclidean image of Antonio Conselheiro.

Keywords: Brazilian Administration; Social Moviments; Canudos; Institutionalism

\footnotetext{
* Trabalho apresentado à área de teoria das organizações do XXX Encontro da Associação Nacional de Pesquisa e Pós-graduação em Administração (Enanpad), realizado em Salvador (BA), de 24 a 27 de setembro de 2006.

1 Doutor em Administração, pela EAESP/FGV. Mestre em Administração Pública, pela EBAP/FGV. Professor da EBAPE/FGV. Praia de Botafogo, 190 - sala 515 Botafogo. Rio de Janeiro - RJ - Brasil - CEP: 22250-900. E-Mail : pemiliom@fgv.br

Artigo recebido em novembro de 2006 e aceito para publicação em janeiro de 2007
} 


\section{Introdução}

A experiência social de Canudos, o Bello Monte de Antônio Conselheiro, na tese euclidiana, é explicada pelo confronto entre o Brasil moderno do litoral e o universo retrógrado de seu sertão. A lucidez do imortal poeta de Os sertões, muito mais do que produzir um relato de guerra de incomparável beleza estilística, legou à historiografia pátria a primeira explicação desse trágico evento testemunhado pelo jovem engenheiro-repórter de $O$ Estado de S. Paulo.

Com base na dialética do então desconhecido escritor fluminense, a explicação daquele episódio se sustenta na contraposição de dinâmicas que se negam no encontro de dois diferentes estágios civilizatórios: o Brasil do litoral, educado, europeizado, rico, dominador e cêntrico e seu sertão, analfabeto, pobre, servil e periférico. A análise formulada no grande épico brasileiro antecipa, assim, as teorias do dualismo social e da dependência, elaboradas somente décadas após.

Neste artigo, essa dinâmica é analisada com base em três dimensões que se determinam reciprocamente na práxis dos relacionamentos sociais. São elas: a política, a religiosa e a econômica, sem, todavia, olvidar a advertência de Goulart, Vieira e Carvalho (2005) de que "a complexidade advém do imbricamento de variáveis sociais [...] que evidentemente exclui a possibilidade de isolamento de uma delas como recurso explicativo da mudança e de seus impactos". A análise do modelo de organização e do sistema de poder/autoridade, implementadores-gestores do projeto do Bello Monte de Antônio Conselheiro, convida à investigação sobre esses importantes vetores do universo organizacional e seus imbricamentos, quiçá os mais relevantes para a compreensão da tecedura social daquela comunidade e da própria sociedade brasileira.

A lógica de organização que presidiu a fracassada tentativa de mudança da cruel ordem social sertaneja é aqui estudada através do modelo de produção que os jagunços desenvolveram sob a liderança do Bom Jesus Conselheiro. Dito de outro modo, a organização social e o sistema de gestão da utopia conselheirista, de acordo com a reflexão aqui feita, resultam da experiência, de quase um quarto de século, em que o povo sertanejo penitente viveu edificando obras pelos sertões, e da pedagogia que o taumaturgo de Quixeramobim elaborou para conduzir sua gente, inspirada no exemplo de Cristo, lutando pela sobrevivência em um ambiente natural hostil e numa economia de grande escassez, intentando a libertação de uma ordem política autoritária, exploradora, violenta e injusta.

\section{A estratégia de investigação}

Para Pettigrew (1985), contextos e organizações se modelam reciprocamente em permanente dinâmica. Dessa perspectiva - de ver além da organização - a análise institucional propõe o desafio de descortino dos espaços da inter/transdisciplinaridade. No estudo que se segue, essa transdisciplinaridade nos levou às fronteiras das teorias das organizações, na tentativa de compreender o fenômeno organizacional ocorrido na Canudos conselheirista (1893-97) e sua improvável, mas destacável, resistência a um esforço de guerra que envolveu quase a metade do efetivo da força terrestre brasileira da época, além de diversos batalhões de quatro forças públicas estaduais (AM, BA, PA e SP). Por outro lado, mais do que esse significativo esforço bélico, o próprio crescimento populacional da vila conselheirista, estimado em $10335 \%$ em pouco mais de quatro anos (MARTINS, 2001, p.73), já aponta no sentido de um relevante fato administrativo, ainda que de trágico desfecho.

A estratégia de investigação elaborada para o enfrentamento desse desafio utiliza-se assim da análise institucional, da semiologia e da historiografia sobre o fato, através do estudo dos depoimentos de descendentes dos sobreviventes da guerra, dos relatos de seus cronistas-testemunhas e dos documentos remanescentes. 


\section{0 processo de institucionalização do conselheirismo}

Os traços diferenciadores e identificadores do que se poderia denominar uma ideologia conselheirista têm como um dos pilares de sustentação o catolicismo da gente do sertão. Essa forma de significação do transcendente resulta (naquela sociedade) dos processos de assimilação do distante cristianismo medieval, trazido pelo colonizador ibérico para os trópicos e de seu sincretismo com a espiritualidade dos povos ameríndio e africano, subjugados e/ou importados como escravos pelo europeu invasor. Para alguns, messiânico, milenarista, sebastianista, o pensamento religioso que iria se consolidar nas terras da caatinga conservaria a magia do sagrado, na sua versão lusitana (difundida em nosso país, principalmente, pelos representantes da Companhia de Jesus), mesclado aos interesses político-econômicos da coroa portuguesa, impostos ao colonizado nas ordenações elaboradas à distância, por um governo de população muito reduzida e empenhado, ao mesmo tempo, na conquista dos mares e na dificílima empreitada de ocupar um território de dimensões continentais e civilizar sua gente. De tão desafiadora missão, resultaria um modelo singular de cristianismo - moralista e permissivo -, proclamador de uma fraternidade universal e escravista, pregador da penitência purificadora e, até certo ponto, hedonista, embriagado pela exuberância do ambiente tropical paradisíaco, autoritário, como representante oficial da metrópole exploradora, e libertário, como porta-voz da palavra de Deus, místico e mesclado da espiritualidade dos povos-atores de nosso processo civilizatório. A um só tempo, uma religião de Deus e de César, instituidora, na cultura pátria em gestação, de uma propensão para o descompromisso entre a o discurso e a prática.

Na moldura que assim se desenha é que o representante oficial da Igreja de Roma no sertão amalgamaria os signos de um credo moralista-dogmático com os do pragmatismo utilitarista da missão colonizadora. Dessa contradição e da tentativa de superá-la é que o universo tabaréu conceberia os fenômenos de liderança religiosa-política dos padres Ibiapina (Ceará, Paraíba, Pernambuco, Piauí e Rio Grande do Norte, 1860-83) e Cícero (Juazeiro, CE, 1872-1934) e dos beatos Antônio Conselheiro (sertões da Bahia e de Sergipe, 1874-97), João e José Maria (Santa Catarina/Paraná, Contestado, 1912-16) e José Lourenço (Caldeirão, CE, década de 1930), entre tantos outros.

Um segundo pilar de sustentação do que se poderia chamar de uma ideologia tupiniquim sobre o trabalho provém da dimensão política da formação de nossa nacionalidade, sendo também marcado pelo confronto de dois princípios antinômicos: as idéias libertárias do pensamento social forjado na Europa do Iluminismo, das revoluções burguesa e Industrial e do pensamento socialista do século XIX - sustentáculos dos ideais abolicionistas-republicanos - e a realidade de um país que foi colônia até quase o final do primeiro quartel do século XIX, que praticou o modo de produção escravista até a penúltima década daquele período e a servidão, em muitos casos, até os nossos dias

O modelo centralizado e autoritário de Estado que tem na figura do "coronel" a representação local do poder central, anteriormente desempenhado pelo capitão-mor do período colonial, como o catolicismo sertanejo, é também profundamente contraditório, ao contrapor as idéias mal-assimiladas de um pensamento progressista com o anacronismo de formas de organização econômica e social de há muito superadas.

O projeto de "reinvenção do sertão" (MARTINS, 2001) que Antônio Conselheiro engendrou, como tantas outras experiências sociais inovadoras e malogradas, parece ter-se baseado num modelo político de Estado teocrático, de inspiração cristã e participativa, de concepção comunitária - modelo das fraternidades do cristianismo rústico -, cujos referentes Conselheiro foi buscar na leitura dos textos evangélicos, como bem atestam suas duas obras manuscritas (CONSELHEIRO, 1895, 1897) encontradas no Santuário, entre os escombros da ex-morada do chefe do povo penitente e sede do governo do Bello Monte e seu corpo, sepultado nos dias derradeiros da grande tragédia sertaneja.

A representação central das definições de administração refere-se à natureza social do fenômeno, isto é, ao fato de ser o mesmo, necessariamente, uma ação coletiva, o que significa dizer que envolve o trabalho societariado. Por outro lado, a semiologia dos referentes do mundo organizacional se dinamiza no processo de significação dos elementos constituintes desse espaço, o qual, por sua vez, se constrói na práxis (histórica) da vida da 
organização social, ou melhor, nos seus processos de adaptação e integração ao universo simbólico maior em que se insere.

Marx, em Miséria da filosofia, já advertia para o fato de que os homens, ao estabelecerem as relações sociais de acordo com o desenvolvimento de sua produção material, criam também os princípios, as idéias e as categorias de acordo com suas relações sociais, sendo, assim, "estas idéias, estas categorias, [...] tão pouco eternas como as relações que exprimem. São produtos históricos e transitórios”. (MARX, 1981, p.88).

Assim entendido, o trabalho societário, ao estabelecer a práxis que irá definir a semiose (traços ideológicos, isotopias e estereótipos) segundo a qual as relações sociais adquirem significado, resume a própria dinâmica do universo organizacional.

Esse terceiro pilar do que se poderia denominar uma ideologia administrativa brasileira, a dimensão econômica, na análise que fazemos da comunidade belomontense é vista no sentido restrito do modelo de produção sertanejo. Mais uma vez, amálgama dos legados de duas culturas antipodais. De um lado, temos a tradição muito forte do trabalho coletivista, herdado das três principais matrizes étnicas da formação do povo brasileiro, isto é:

1) dos adjuntos minhotos, das vezeiras, das lamas de boi, dos moinhos do povo, do forno comum, do rogar, das vessadas, das segadas e de tantas outras formas de trabalho solidário e de ajuda mútua, legados pelo colonizador lusitano;

2) do apatxiru dos tapirapés, do magaru (caça coletiva) dos bororos e das formas assimiladas da tupambae (coisa de Deus) e da amambae (coisa do homem), essas últimas desenvolvidas pelos jesuítas da região missioneira do Sul e adaptações da tradição coletivista do aborígine sulamericano; e

3) da morança dos manjacos e das montarias (caça coletiva) dos mandigas da Guiné portuguesa, dos partidos de trabalho (limpeza e lavoura coletiva do solo), dos bambas da África Equatorial Francesa, das ayar ayong (cooperativas de trabalho para construção de casas, caminhos, derrubadas etc.) dos fang do Gabão do Norte, do donkpê do Reino de Dahomey etc. (CALDEIRA, 1956) práticas legadas pela contribuição africana à formação de nossa gente.

De outro lado, temos o modelo de produção da monocultura de base escravista do grande latifúndio - herança da política colonial das sesmarias e dos poderes autoritários de representação real do capitão-mor e, posteriormente, de seu sucessor histórico: o "coronel".

Leal (1975) assim resume os traços principais desse fenômeno político, muito forte no processo de constituição cultural de nossa nacionalidade:

Conquanto suas conseqüências se projetem sobre toda a vida política do país, o "coronelismo" atua no reduzido cenário do governo local. Seu habitat são os municípios do interior, o que equivale a dizer os municípios rurais, ou predominantemente rurais; sua vitalidade é inversamente proporcional ao desenvolvimento das atividades urbanas, como sejam o comércio e a indústria. Conseqüentemente, o isolamento é fator importante na formação e manutenção do fenômeno. $(1975$, p.251)

Embora Cunha (1902) tenha o mérito de haver intentado a primeira explicação sociológica para o fenômeno Canudos e a coragem de não resistir ao impulso de revelar-se um pensador em franco processo de crise com seu referencial teórico, sua análise ratifica a figuração que a visão litorânea tem do sertão, segundo os signos elaborados pelas culturas dos centros industrializados, mais próximos dos de nossa cultura litorânea e inteiramente divorciados do universo simbólico periférico sertanejo. Essa leitura, típica do intelectual brasileiro do final do século XIX, levou o genial autor do grande épico brasileiro a uma interpretação projetada do fenômeno em estudo, equívoco esse que iria marcar a historiografia de Canudos por mais de meio século, dado à força do discurso daquele escritor e seu estilo inimitável.

Se concordarmos que a organização social do Bello Monte deriva principalmente de sua ideologia religiosa, é também inegável que essa religiosidade, com seu apelo cristão de construção de uma fraternidade universal, 
estabeleceria os traços identificadores no processo semiótico de leitura/captura do referente modo de produção sertanejo e que, desse desenvolvimento, só poderia resultar uma. concepção de trabalho mutualista, cooperativo, solidário ou, numa única palavra, fraterno. O adjunto sertanejo, prática intensamente utilizada pelas comunidades rurais do sertão brasileiro até os nossos dias, é o produto cultural mais genuíno dessa práxis laborativa. Esse sistema produtivo, de inspiração autogestionária, é também o modelo teórico de organização das comunidades dos socialistas românticos, como Saint-Simon, Proudhon, Fourrier e Owen.

Sobre essa questão, Moniz afirma que Antônio Conselheiro teria buscado na Utopia (1516?) de Thomas More o modelo teórico para seu projeto social. Essa afirmativa polêmica tem suscitado a indignação de alguns historiadores. Em uma das entrevistas que aquele professor (hoje falecido) concedeu a este pesquisador, quando interpelado sobre o assunto, Moniz destacou que, ao tempo de Antônio Conselheiro, o grande clássico do pensamento utópico, escrito originalmente em latim, já fora traduzido para o francês; que o beato-peregrino havia estudado esses dois idiomas na sua infância em Quixeramobim; que, tendo sido o autor da Utopia canonizado, era muito provável que a mesma fosse acessível ao pregador sertanejo, entre os textos sagrados existentes nas prelazias por onde peregrinou e, finalmente, que o demiurgo do sertão, em suas prédicas, referese, textualmente, ao pensador inglês, ao incluí-lo entre os "varões sábios e prudentes", cujo destino "era encher as religiões, povoar os desertos, deixar as riquezas e desprezar o mundo" (MONIZ, 1987, p.100).

Resumindo, o modelo de trabalho cooperativo de ajuda mútua, originário do meio rural e presente, como vimos, nos três vetores de formação cultural de nosso povo, sincretizaria-se, nos sertões brasileiros, nas formas regionais do adjunto ou adjutório cearense (experiência social do, também trágico, episódio do Caldeirão), nas arrelias da Paraíba, nas faxinas do Rio Grande do Norte, nas tapagens (fechamento de um braço do rio para pesca coletiva), nas juntas pernambucanas, no batalhão ou adjunto, na traição ou roubo e nos bois-roubados (essas duas últimas denominações devidas ao sentido de surpresa que esses modelos de ajuda mútua assumem), largamente empregados na região da caatinga, conforme Caldeira (1956). Em outras palavras, são esses os traços ideológicos que processaram a semiose do referente estudo na comunidade conselheirista, a qual se desenvolveria com a prática disseminada do modelo mutualista de produção, o que equivale dizer: Canudos foi um grande mutirão e Antônio Conselheiro seu organizador e gestor.

O grau de institucionalização de uma organização pode ser avaliado pela complexidade dos signos (inclusive os dramatúrgicos) socialmente pactuados que seu sistema cultural elabora no dia-a-dia da vida comunitária. Assim, os ritos, cerimoniais, desempenho de papéis, "fabricação de heróis" e mitos, bem como as "historinhas" de cunho moral são produtos culturais reveladores do desenvolvimento institucional da organização.

A Companhia do Bom Jesus começa a manifestar os primeiros sinais de um processo de institucionalização em franco curso, já na sua primeira fase de existência, bem antes de se instalar nas margens do Vaza-Barris para dar consequiência ao seu projeto terminal. Após a primeira notícia na imprensa, que se conhece, dando conta da vida do bando errante, francamente desfavorável ao grupo e ao seu líder (O RABUDO, 1874), localizamos na Folhinha Laemmmert, publicada na capital do Império, dois anos depois, a seguinte nota reveladora do crescimento institucional do grupo e do prestígio de seu chefe:

Apareceu no sertão do Norte um indivíduo, que se diz chamar Antônio Conselheiro, e que exerce grande influência no espírito das classes populares servindo-se de seu exterior misterioso e costumes ascéticos, com que impõe à ignorância e a simplicidade. Deixou crescer a barba e cabelos, veste uma túnica de algodão e alimenta-se tenuemente, sendo quase uma múmia. Acompanhado de duas professas, vive a rezar terços e ladainhas e a pregar e dar conselhos às multidões, que reúne, onde lhe permitem os párocos; e, movendo sentimentos religiosos, vai arrebanhando o povo e guiando-o a seu gosto. Revela ser homem inteligente, mas sem cultura. (apud CUNHA, 1982, p.111)

A cronologia do processo de institucionalização do grupo conselheirista tem sequiência no precioso relatório do frei João Evangelista de Monte Marciano, chefe da malograda missão religiosa enviada ao Bello Monte e publicado em 1895. Também fortemente tendencioso, quer pelo insucesso de sua infeliz missão como, ainda, segundo o próprio documento, pelas ameaças que teria sofrido seu chefe durante sua estada no arraial, esse depoimento é muito rico de informações sobre o processo de institucionalização da comunidade. Vejamos alguns fragmentos desse raro e precioso documento: 
Refeitos um pouco de nossa penosa viagem, dirigimo-nos para a capella onde se achava então Antonio Conselheiro, assistindo aos trabalhos de construção; mal nos perceberam, os magotes de homens armados cerraram filleiras junto á porta da capella, e ao passarmos, disseram todos: 'Louvado seja Nosso Senhor Jesus Christo', saldação frequente e comum, que só recusam em rompimento de hostilidades. Entrando, achamo-nos em presença de Antonio Conselheiro, que saudou-nos do mesmo modo.

Vestia tunica de azulão, tinha a cabeça descoberta e empunhava um bordão: os cabellos crescidos, sem nenhum trato, a cahirem sobre os hombros: as hirsutas barbas grisalhas, mais para brancas; os olhos fundos, raras vezes levantados para fitar alguem, o rosto comprido e de uma pallidez quase cadaverica; o porte grave e ar penitente, davam-lhe ao todo uma apparencia que não pouco teria contribuido para enganar e attrahir o povo simples e ignorante dos nossos sertões. [...]

Á porta da capella e em varios pontos da praça apinhavam-se perto de mil homens armados de bacamarte, garrucha, facão, etc. [...]

Usam elles camisa, calça e blusa de azulão, gorro azul á cabeça, alpercatas nos pés [...]

Abri a missão a 14 de maio [...] O Conselheiro tambem veio, trazendo bordão: colocava-se ao lado do altar, e ouvia attento e impassivel; mas, como quem fiscalisa, e deixando escapar alguma vez gestos de desapprovação que os maioraes da grei confirmavam com incisivos protestos. [...].

Entre essa turba desorientada, há varios criminosos, segundo me affirmaram, citando-se até nomes, alguns dos quaes eu retive, como o de João Abbade, que é alli chamado o 'chefe do povo' [...]

[...] pode-se dizer que é aquillo um estado no Estado (sic). (MONTE MARCIANO, 1895).

A riqueza de detalhes sobre os já complexos sinais de institucionalização da organização comunitária, como, por exemplo, a saudação "Louvado seja Nosso Senhor Jesus Cristo!", cuja resposta devida é "Para sempre seja louvado tão bom Senhor!" (ainda hoje usada pelos canudenses e equivalente ao nosso Bom-dia! litorâneo); a Guarda Católica uniformizada, organizada para defesa do arraial e proteção pessoal de seu chefe; a encenação de papéis dramatúrgicos, durante os atos na igreja, descrita pelo frei italiano e tantos outros sinais que levaram o religioso capuchinho à conclusão de "[ser] aquillo um estado no Estado" (sic) são um convite muito forte ao aprofundamento do grau de organização alcançada pela Companhia do Bom Jesus naquele ano que antecederia o início da guerra fatal. Sigamos, entretanto, analisando outro depoimento, posterior ao relatório do frei Monte Marciano ao arcebispado baiano, também de grande riqueza.

Na sua edição de 18 de dezembro de 1895, o Diário da Bahia publica uma carta do juiz preparador da Vila do Bom Conselho, Pedro Baptista do Espirito Santo, datada de 7 do mesmo mês, relatando a chegada de Antônio Conselheiro e seu "séquito" àquela vila. Sendo esse depoimento também contrário à gente do Bello Monte e seu líder, apresenta, contudo, minucioso relato do estágio avançado de institucionalização da organização sertaneja, comparada às instituições locais coetâneas, à exceção, obviamente, da própria Igreja e do "coronelismo".

As dez horas do referido dia 5, a nossa expectativa foi muito alem do que imaginavamos. $O$ som aspero de uma musica marcial, o estrugir de foguetes que de espaço em espaço fendiam os ares a vozeria descompassada de mais de mil boccas que em som cavernoso repercutia pelas quebradas das montanhas o écho de "viva o bom Jesus! viva o nosso Conselheiro! Viva a monarchia" annunciavam o momento de sua entrada triunphante nesta nova Jerusalem. [...].

De subito surgio, envolta em densa nuvem de poeira, a primeira ala, composta de 12 homens vestidos de camisola azul, no centro dos quais destacava-se um velho magro de côr macilenta, barba longa e grisalha, cabbelos compridos e esparsos em desalinho pelos hombros. Vestindo uma tunica branca e segurando um bastão, que lhe servia de arrimo aos vacilantes passos.

O vulto que assim se differenciava dos outros era Antonio Conselheiro. 
Os 12 homens de camisola azul, atada á cinta por um grosso e cumprido cordão, arrematado por duas bolas, tendo sobre a cabeça um gorro da mesma côr, são os de sua maior confiança e por isso tem a denominação de Apostolos, e como taes são tidos e respeitados.

Em seguida, uma Segunda ala de cerca de vinte homens bem armados e uniformisados, e como esta mais cinco ou seis, iam successivamente mostrando-se aos olhos dos expectadores. Após esta columna de mais de 100 homens, o grosso do exército em ordem de quatro a quatro formava em continuo e lento movimento uma extensa linha de mais de 100 metros. [...]. (sic) (ESPIRITO SANTO, 1895)

É flagrante que um sistema social que alcança o grau de institucionalização como o assim manifesto nas hierarquização, dramatização e coreografia dos eventos relatados pelo frei Monte Marciano e pelo juiz preparador de Bom Conselho desenvolve-se sob a influência de algum tipo de poder/autoridade, revelando já ter atingido um certo grau de consenso coletivo no estabelecimento dos papéis, condutas, normas e objetivos que orientam a vida comunitária, bem como de desempenho e distribuição desses papéis entre seus atores.

Esse ponto é fulcral para a melhor compreensão do episódio Canudos porque, a partir dele, pode-se enveredar por duas diferentes e antinômicas trilhas na significação do fenômeno, a saber:

1) elaborar a semiose de seus significantes a partir dos códigos estabelecidos por outra cultura e, conseqüentemente, descodificar os seus referentes com traços ideológicos alienígenas. Essa parece ter sido a leitura euclidiana e de seus coetâneos e epígonos, até quase o final dos anos 1940. Na obra-prima daquele escritor este posicionamento fica claro na confissão que faz: "No arraial, porém, exigia, digamos em falta de outro termo - porque os lexicons não o têm para exprimir um tumulto disciplinado, - ordem inalteravel". (CUNHA, 1902, p.200). Também na musicografia do tema, os versos de Cacaso na melodia de Edu Lobo exprimem a mesma perplexidade litorânea ante o desafio de ler os signos da cultura sertaneja: "Que horizonte mais errante!/ Que crendice mais descrente!/ Que descrença mais distante!/ Que distância mais presente!/ Desgoverno governante/quanta gente confiante/ em Antônio penitente". (LOBO; CACASO, 1978). Do mesmo modo, a iconografia "praiana" (no sentido de litorânea, conforme sua significação sertaneja) codifica a imagem do poder/autoridade de Antônio Conselheiro com sinais que evocam traços de uma personalidade enérgica, mas com gestos irados, arrogantes, convulsivos e vesânicos. O belíssimo trabalho escultórico, representando o profeta em pregação, de autoria do artista plástico Mário Cravo, aproveita o movimento natural de um tronco de árvore que se divide em três frondosos galhos, para lançar no espaço, em magistral obra de talha, o gesto tresloucado dos braços e da cabeça do Bom Jesus Conselheiro - o mesmo pregador que pedia aos seus seguidores genuflexos que se erguessem, afirmando: "só Deus é grande". Esses códigos também estão presentes no desenho com o qual Carybé e seu genial traço retratam o beato orador com os membros superiores se multiplicando nos rápidos movimentos circulares que executam, qual uma Shiva sertaneja enlouquecida; e

2) outra possibilidade de ler Canudos convida ao exercício da investigação participante e busca a leitura dos códigos semiológicos de um povo segundo a semiose da mesma práxis que os engendrou. Para este pesquisador a orientação de seguir essa metodologia ficou clara quando, perguntando a Adonel Mattos (canudense, descendente dos sobreviventes da Guerra de Canudos, 4 de fevereiro de 1995) como ele podia ter certeza de que um soldado da $3^{\underline{a}}$ Expedição, fugitivo e sem farda, acidentalmente encontrado na caatinga por um jagunço seu ancestral, era mesmo um combatente das tropas republicanas, ouvimos a resposta: "os trajes de um eram de um mundo; os outros, de outro".

\section{Governança e processo decisório do Bello Monte}

A tese de que a prática do mutirão teria inspirado um modelo autogestionário de decisão na governança do Bello Monte parece se confirmar nos depoimentos dos descendentes dos conselheiristas: 
Eles [os conselheiristas] trabalhavam em conjunto. Ninguém tinha nada. Todo mundo fazia roça, todo mundo trabalhava. Colheu... Colheu. Toma o seu... Toma o seu. Ninguém ficava com menos ou com mais (sic). (ADONEL RÉGIS MATOS, canudense, 1932, depoimento dado em Canudos, 4 de fevereiro de 1995)

Vamos trabalhar e se unir. Aqui todos são iguais. Eu [Antônio Conselheiro] sou igual a vocês (sic). (ZEFINHA, canudense, 1916, depoimento concedido em Canudos, 6 de fevereiro de 1995)

As casinhas eram de taipa; construídas nos mutirões. O arraial cresceu em quatro anos porque tinha ajuda de uns aos outros (sic). (JOÃO DE RÉGIS, canudense, 1907, depoimento em Canudos, 4 de fevereiro de 1995)

O povo aqui era todo de mutirão. Fazia as coisas ... Tudo... Ninguém não ganhava dinheiro não (sic). (MADALENA ANTÔNIA DOS SANTOS, canudense, 1950, sobrinha de Manezão - afilhado de Antônio Conselheiro -, Canudos, 4 de fevereiro de 1995)

[Antônio Conselheiro] reunia as pessoas para decidir sobre a vida do arraial.

Conselheiro combinava tudo com o seu grupo e partia para a ação (sic). (ZEFINHA, Canudos, 6 de fevereiro de 1995)

Também entre os cronistas-testemunhas do episódio, quase todos opositores e/ou combatentes contra o movimento liderado por Antônio Conselheiro, surgem indicações de que Canudos logrou desenvolver um modelo autônomo de economia e que esta se baseava na produção de base mutualista e na decisão colegiada:

O certo é que [Antônio Conselheiro] abria aos desventurados os celeiros fartos pelas esmolas e produtos do trabalho comum. (CUNHA, 1982, p.132)

Ao romper da barra já se ouvia o baque surdo das enchadas e picaretas, cavando, no leito de um riacho que nascia nas plantas de uma montanha [...]

O furor e a boa vontade de todos, suppriam a escassez de instrumentos, e a obra apparecia a olhos vistos (sic). (BENICIO, 1899, p.97)

Todo o povoado agitava-se; trabalhavam todos e A. Conselheiro, impassivel, presidia á todo aquelle movimento (sic). [...]. (MACEDO SOARES, 1903, p.37)

É ainda entre os cronistas-testemunhas que encontramos o mais forte depoimento sobre a prática do processo decisório colegiado no governo da comunidade do Vaza-Barris. Referindo-se às providências dos jagunços para o enfrentamento das forças da $4^{\mathrm{a}}$ Expedição, aquele repórter do Jornal do Commercio do Rio de Janeiro registra: "Conselheiro reunira o Senhedrin e interrogou os maioraes". (sic BENICIO, 1899, p.244)

Para os historiadores contemporâneos, também crentes na auto-sustentabilidade econômica do arraial, Conselheiro e seus seguidores foram buscar nas raízes culturais de seu universo simbólico/ideológico os princípios determinantes do modo de produção que viabilizou seu projeto:

O sertão de Antônio Conselheiro, como até hoje, encontrava-se no contexto da desigualdade de ritmo e do desenvolvimento combinado das regiões subdesenvolvidas. Canudos não podia fugir à regra. À agricultura e ao pastoreio organizados em forma comunal, como um "falanstério", ajustava-se, por meio da exportação do couro, a participação no mercado mundial. Havia uma conexão entre a produção primitiva de Canudos e a colocação de um de seus produtos no mercado europeu. No sertão semifeudal, surgia uma nova forma de experiência social, semelhante às de Fourier e de Owen. (MONIZ, 1987, p.78)

A organização econômica da comunidade seguia a tradição sertaneja. Os conselheiristas, desde os anos de peregrinação, adquiriam o gado por meio de esmolas, caçavam e auxiliavam os pequenos agricultores no plantio e colheita através de mutirões. (VILLA, 1995, p.64) 
Entre os pioneiros da historiografia econômica de Canudos, do mesmo modo que entre os descendentes dos sobreviventes da guerra e os cronistas-testemunhas do episódio, é comum a idéia da prática do mutirão como forma característica de divisão do trabalho no Bello Monte:

É possível que a posse da casa e da terra tenha sido privada e o produto da terra, coletivo. A única certeza é que muitas atividades eram realizadas em mutirão, em particular a construção das casas e o trabalho da terra. (GARCEZ apud BLOCH, 1997, p.88)

[...] quase todo mundo admite hoje que a organização econômica do arraial inspirava-se na tradição sertaneja. Em particular, o mutirão deve ter sido uma prática corriqueira, especialmente para o trabalho da roça e a construção das casas.

O projeto do "êxodo" de Antônio Conselheiro[...] resulta num retorno utópico à vida da comunidade cristã primitiva. A vivência desta comunidade, a "vita communis", é o ideal popular de uma sociedade justa e fraterna, na qual igualmente são atendidas tanto as exigências de Deus quanto os anseios humanos de uma vida digna. [...].

Antônio Conselheiro reaviva o capital latente do catolicismo popular, então decadente, inovando-o e religando-o às suas raízes. (OTTEN, 1990, p.366)

Por outro lado, também está presente entre os estudiosos de Canudos a idéia de que a práxis do trabalho mutualista teria criado as condições para o surgimento da decisão colegiada entre os habitantes daquela comunidade:

As relações religiosas passam a constituir relações de autoridade no grupo, ficando hierarquicamente privilegiados quanto ao poder de mando aqueles que reproduzem com maior fidelidade a doutrina igualitária cristã na vida prática. (BARROS, 1988, p.149)

Canudos foi o grande momento da história nordestina do final do século XIX e significou a negação radical de uma sociedade marcada pelo racionalismo cientificista, pelo mandonismo e pela lógica do capital, acabando por se transformar em uma das maiores referências da História do Brasil. (VILLA, 1995, p.244-245)

Antônio Conselheiro sabia ouvir atentamente as sugestões dos companheiros de confiança a quem estimava e escolhia para dar as incumbências difíceis. No "santuário", reunindo os elementos mais responsáveis da cidade, discutia com eles, horas seguidas, as medidas necessárias à administração e defesa de Canudos. (MONIZ, 1987, p.130)

Finalmente, Bloch (1997) deixa clara a institucionalização no Bello Monte da filosofia mutualista-participativa na vida da comunidade:

Essa organização econômica, porém, foi provavelmente além da simples ajuda mútua no dia-a-dia, se admitirmos que o fundo comum institucionalizava a solidariedade ao permitir a redistribuição de parte dos excedentes. (Ibid., p.87-88)

Registra-se, entretanto, na historiografia do movimento religioso-social da caatinga a tese de que teria existido em Canudos uma sociedade mercantilista, baseada na propriedade privada (inclusive da terra), na exploração do trabalho e na estratificação social. Esses autores justificam essa idéia através do suposto enriquecimento da família Vila Nova, proprietária do principal empório comercial local e da trágica disputa pelo monopólio do mercado da vila, que se teria travado entre aquela família e a família Motta - antiga habitante da região e que lá se estabelecera no local antes da chegada dos Vila Nova a convite de Conselheiro. Afirmam, ainda, esses historiadores que a divisão da sociedade canudense em classes sociais ficou comprovada na arquitetura das bem-construídas casas de telha, de propriedade da elite econômica do arraial, e pelos milhares de miseráveis casebres habitados pela população pobre dos bairros periféricos, como demonstram as fotografias de Flávio de Barros - fotógrafo contratado pelo Exército para fazer a reportagem oficial da guerra. 
Como contestação a esses argumentos, fica a lembrança de que o Bello Monte viveu sua breve experiência de "reinventar o sertão" sob o fogo de uma cruel e desproporcional investida militar, que durou quase um quarto da vida do povoado, e que, provavelmente, empenhado nesse esforço bélico superior, o projeto de transformar o sertão sucumbiu à crítica situação de defesa do território sitiado e bombardeado e à desintegração de sua sociedade.

\section{A estrutura de organização/decisão do "sertão reinventado"}

$\mathrm{O}$ advento da sociedade industrial traria para o mundo das organizações as condicionantes que iriam determinar um crescente aumento de complexidade nas suas estruturas de poder, cada vez mais estratificadas e departamentalizadas. É muito provável que o engenheiro francês Henri Fayol (1841-1925) tenha sido o primeiro a definir a função da organização no contexto do mundo industrial de produção massiva que então alvorecia. Com efeito, quando o mais importante clássico das teorias organizacionais européias definiu a ação administrativa como a previsão, a organização, o comando, a coordenação e o controle das atividades orientadas para a consecução de um determinado propósito, cuidou também de analisar cada uma dessas funções definindo, então, organizar como o ato de "constituir o duplo organismo, material e social da empresa". (FAYOL, 1968, p. 21).

Em sua obra Administration industrielle e généralle (1916) aquele autor destaca a competência organizacional como pré-requisito indispensável a todo administrador. É possível que, da preocupação de anatomizar o aparelho social das empresas, para melhor controlá-lo, tenham se originado os organogramas, com seu poder de síntese, visão relacional das partes e capacidade de informar melhor e mais rapidamente do que os velhos estatutos, regimentos e manuais de organização. Assim, esses signos gráficos representativos dos arranjos dos sítios de poder e suas relações formais se transformaram nos significantes mais utilizados para comunicação da estrutura política das organizações.

É evidente que Antônio Conselheiro e seus coetâneos do Vaza-Barris ignoravam completamente as interpretações teóricas do mundo industrializado, como as que inspiraram a obra de Fayol, como é também certo que o analista, ao pretender traduzir um tempo passado para a época presente, não pode fugir da fatalidade de incorrer na advertência do aforismo italiano: traduttore traditore!

Ainda que incursos nesse risco, não resistimos à tentação de analisar a estrutura de poder que implementou e geriu o projeto do Bello Monte, com o suporte de teorias mais recentes.

Em seu trabalho Structure in fives: designing effective organizations (1983), Mintzberg propõe um modelo para leitura das estruturas organizacionais composto de cinco partes assim denominadas: strategic apex (nível ou ápice estratégico), middle line (faixa ou nível gerencial), operating core (núcleo ou nível operacional), technostructure (tecnoestrutura) e support staff (apoio, assessoramento).

É claro que no seu modelo Mintzberg analisa a organização burocrática contemporânea. Entretanto, em sua obra, o autor discute as diversas configurações que as estruturas organizacionais podem assumir na sua história evolutiva, da mais simples (The simple structure - apenas um núcleo estratégico subordinando, diretamente, o núcleo operacional) à mais complexa, composta das cinco partes. Segundo esse autor, essas configurações se dão em função do que ele denomina pulls (puxões), aos quais estariam sujeitas qualquer uma das cinco partes anatômicas de seu modelo organizacional, no eterno jogo político que travam entre si.

De acordo com MARTINS (2001), a interpretação e tradução para a linguagem mintzberguiana da estrutura de organização do projeto de Antônio Conselheiro nos convida a distinguir as distintas fases de seu processo evolutivo e as configurações que o mesmo assumiu:

$1^{\circ}$ ) período que vai, provavelmente, de junho de 1874 [quando O Rabudo, tablóide de Estância (SE), publica a primeira notícia que se conhece do beato-peregrino] até maio de 1893 [combate de Masseté e conseqüente necessidade do grupo conselheirista abandonar o município de Itapicuru e o arraial do Bom Jesus (atual Crisópolis) e interiorizar-se ainda mais pelos sertões]. MARTINS (2001) denomina 
"religiosa-assistencial" essa primeira fase que compreende o período nômade do grupo, que peregrina pelas províncias/estados da Bahia e Sergipe. Nesse lapso, o beato de Quixeramobim se transforma no Conselheiro do povo errante do sertão e passa a gozar de grande poder de influência sobre seus liderados. É também nesse período que se edificam as obras religiosas-sociais do construtor-pregador, com exceção dos templos e cemitério do Bello Monte. Essas edificações, espalhadas por uma área maior do que o atual estado de Sergipe, algumas realizadas simultaneamente - provavelmente, a capela do Bom Jesus da atual Crisópolis e a igreja do Senhor do Bonfim do Capim Grosso (hoje Chorrochó) -, exigiram de seu construtor competência logística e capacidade de liderança, além de considerável vigor físico.

Durante essa primeira etapa, a organização social do Bello Monte se modela segundo a configuração denominada the simple structure (estrutura simples) na taxionomia de Mintzberg e tem no seu ápice estratégico a autoridade de Antônio Conselheiro; no nível gerencial, os beatos e artífices mais qualificados como Paulo José Rosa, José Beatinho e Antônio Beatinho, entre os "homens-santos", e Manoel Feitosa (ou Faustino), Ricardo Pedreiro e Vitório, entre os artífices. Na base da micropirâmide hierárquica da organização nascente (seu nível operacional), vivia a crescente massa de seguidores do Bom Jesus Conselheiro.

$2^{\circ}$ ) a segunda fase da história do grupo sertanejo, a qual MARTINS (2001) denomina desenvolvimentista-administrativa, compreende o período do apogeu daquela experiência comunitária e é marcada pela fundação e o fantástico crescimento do Bello Monte. Concomitantemente, intensificam-se nessa etapa as articulações político-religiosas e militares do litoral para pôr fim ao projeto de transformação do sertão e ao risco que o mesmo representava de subverter a ordem políticoeconômica coronelista e o poder da Igreja sobre as populações deserdadas do hinterland brasileiro. Esse interregno se estende de junho de 1893 (fixação do povo no pequeno povoado de Canudos) a junho de 1897 [primeiros combates oferecidos aos jagunços pela poderosa $4^{\mathrm{a}}$ Expedição; tomada da passagem de Cocorobó pela $2^{\mathrm{a}}$ Coluna daquele destacamento militar (25/6/1897); combate do Angico pela vanguarda da $1^{\underline{a}}$ Coluna (27/7/1897) e intensificação dos combates contra os conselheiristas, estabelecendo o estado de guerra total que se estenderia até o início de outubro daquele fatídico ano]. Esse é o momento de maturidade do projeto comunitário e de início da morte da inovadora experiência social sertaneja. Nele, a estrutura organizacional assume sua configuração mais complexa e apresenta os primeiros sinais de uma embrionária institucionalização, logo abortada. A liderança do grupo nesse período continua com Antônio Conselheiro, e é muito provável que tenha surgido então um esboço do que poderia ser um colégio decisório comunal, o qual desempenharia os papéis da "tecnoestrutura" e do staff do modelo de Mintzberg. Na investigação que empreendemos, encontramos fortes indícios de que a organização de governo do Bello Monte tenha conhecido esse sistema de governo, sob a presidência de Antônio Conselheiro e com a participação dos denominados "Doze Apóstolos", também referidos como "Companhia do Bom Jesus".

Abaixo desse órgão colegiado de direção viria o estrato intermediário de gestão da comunidade, seu nível tático ou gerencial, aparecendo como seus principais executivos, João Abade - o "comandante da rua" (na linguagem sertaneja a palavra rua é mais empregada no sentido metonímico de vila, cidade ou espaço público.) -, nos assuntos de polícia e defesa militar do arraial; Antônio Vila Nova, verdadeiro prefeito da vila, na administração da urbe, e o próprio Antônio Conselheiro, nas questões de doutrina, justiça e obras sociais.

$3^{\circ}$ ) finalmente, a derradeira etapa de vida da comunidade do Vaza-Barris, de julho a outubro de 1897 (junção das duas colunas, intensificação do bombardeio ao arraial, chegada da brigada federal de reforço Girard e dos batalhões das forças públicas dos estados do Amazonas, Pará e São Paulo), contempla o recrudescimento dos combates oferecidos pelas tropas oficiais, a conseqüente transferência do comando da comunidade para o "consulado" Antônio Vila Nova/João Abade e o massacre e destruição final do povoado. Durante esse período, o Bom Jesus Conselheiro, doente, depois morto (22 de setembro de 1897), teria perdido o controle de sua gente, que passaria a ser liderada por João Abade, seus comandantes de piquetes e Antônio Vila Nova - organizador do abastecimento da vila sitiada. Nesse lapso derradeiro, a organização volta-se, exclusivamente, para o 
esforço de defesa do arraial e reassume a configuração simples da primeira fase, perdendo, assim, sua complexidade e força.

Se é verdadeiro que a dinâmica do capital é a competição e que o sistema de organização econômica que faz face a essa lógica é o de base solidária e ainda, que ao mandonismo se opõe o participacionismo, o ponto de convergência das três teses anteriormente citadas ocorre na equivalência semântica de suas representações nucleares: não-mandonismo, (doutrina) igualitária e "vita communis", evocativas do modelo de administração participativa sugerido pelo teórico Edmundo Moniz, pelo cronista-testemunha, Manoel Benício e, também, por Zefinha - filha de conselheiristas.

O significante poder e autoridade na estrutura de organização do Belo Monte, além da referência administração colegiada, propõe, ainda, uma já bem desenvolvida hierarquização organizacional, alcançando os três níveis clássicos de verticalização/estratificação do poder, a saber, os níveis estratégico, gerencial e operacional, presentes também na anatomização da organização feita por Mintzberg (1975).

O melhor entendimento do poder de Antônio Conselheiro sobre os jagunços convida à contraposição do modelo de autoridade, aparentemente representado pelo chefe do povo do Vaza-Barris, com as outras formas de poder conhecidas pela sua gente: o do "coronel" mandão, explorador e violento; o do cura alienígena, pregador de uma doutrina libertadora pelo sacrifício e, tantas vezes, amancebado com suas fiéis, pai de filhos bastardos; e o do fiscal-corrupto, cobrador dos impostos de um governo desconhecido e completamente ausente.

Os elementos da análise assim formulada são fundamentais para a compreensão da forma de poder/autoridade que Antônio Conselheiro exerceu sobre seus liderados: quiçá (?) uma variante do "coronelismo" com o sinal contrário.

Em sustentação a essa tese, lembramos que o laço de compadrio - característico do modelo "coronelista" também se fazia presente e freqüente na liderança do chefe do povo religioso da caatinga com sua "família", conforme foi constatado durante a fase de investigação de campo desta pesquisa, quando tivemos a oportunidade de ouvir depoimentos de diversos filhos, sobrinhos e netos de afilhados do Bom Jesus Conselheiro.

Assim como as hipóteses de um sistema de governo teocrático e de administração colegiada do Bello Monte, em processo de institucionalização, parecem encontrar respaldo nos relatos dos cronistas-testemunhas, dos descendentes dos sobreviventes e de não poucos estudiosos do tema, a idéia da perda desse poder, por parte de Antônio Conselheiro, ao final da guerra, também corroborada por diversas fontes:

João Abbade confabulou com Conselheiro. O pobre velho ouvi-o melancolico e indifferente a discorrer sobre as medidas a tomar.

Estava num estado de marasmo fakirico em que tantas vezes, agora, engolphava-se.

Quando Abbade pediu a sua approvação. Elle ergueu os fundos olhos onde luzia mais accentuadamente a chamma da loucura que o attacara na mocidade e murmurou como que alheio ao que se tinha passado.

- Seja feita a vontade de Deus (sic). (BENICIO, 1899, p.289)

Pelo menos, em duas outras passagens de seu relato, quase-romance, da guerra que reportou para o hoje mais do que sesquicentenário jornal fluminense, Benício volta a se referir à vacância da magistratura máxima do arraial sertanejo nos seus últimos dias de existência:

[...] o abandono em que vivia Conselheiro e o isolamento a que se consagrara, pouco se dando com o que se passava no arraial. (Id., p.290)

Antonio Maciel cada vez mais arredio, embiocou-se no Santuario, donde raras vezes o tiraram Beatinho e Taramela. 
A verdade é, porém, que o velho monomaniaco sentiu-se reanimado quando, depois de tres dias de combate, os atacantes não tinham ainda tomado Canudos.

Na predica que fez ao seu povo conseguio infiltrar uma dóse do animo e esperança que lhe reveviam na alma.

Chegou a designar alguns homens, dirigidos por Vila-Nova, para diversos cantos do sertão, afim de comprarem farinha, milho, rapadura, etc [...]

Déra liberdade ás mulheres para sahirem do arraial, levando os filhos. (sic) (Id., p.320)

Ainda que contaminado pelo diagnóstico de "delirio chronico (Magman), de psychose systematica progressiva (Garnier), de paranoia primária dos italianos, etc." de Rodrigues (1939, p.53), enfermidades que teriam acometido o líder-transformador do sertão muito cedo, Manoel Benício é, sem dúvida, uma referência muita rica, quer pela oportunidade que teve de presenciar o episódio relatado, quer pela riqueza de detalhes de seu depoimento.

A hipótese do "rei dos jagunços" ter perdido o comando de seu povo, poucos meses antes da consumação de seu trágico destino, é também incorporada pelo eminente professor dr. Nina Rodrigues - então diretor da Faculdade de Medicina da Bahia e chefe da equipe que procedeu ao exame craneométrico de Antônio Conselheiro - na argumentação de seu diagnóstico (psicose sistemática progressiva) da vesânia que acometia o Bom Jesus:

Nos ultimos tempos de sua existencia, vivia Antonio Conselheiro, de facto, afastado da direcção do governo local e completamente entregue a seu papel de Christo ou emissario divino. Como já se viu em 1895, quando da visita dos Capuchinhos, era sempre vigiado pelos seus discipulos, que formavam uma guarda constante em torno delle. Na realidade elles geriam, uns os negocios da guerra, outros da administração interior e civil, outros emfim, que o redeavam de muito perto, lhe serviam de acolytos nas cerimonias do culto.

Uma vez dado o impulso e organizada a seita como estava, acabou Antonio Conselheiro por se tornar o idolo, a divindade; as obras do fanatismo e a lucta provocada por elle eram reservadas especialmente á turba, aos sectários (sic). (RODRIGUES, 1939, p.134-135)

\section{Conclusões}

A viva presença no imaginário do povo brasileiro, mais de um século após o episódio, do massacre da gente de Antônio Conselheiro e da destruição de seu povoado, amplamente testemunhada pela vasta produção cultural que o tema tem inspirado, conjugada à difícil luta pela sobrevivência imposta pelo habitat dos sertões nordestinos, foram os motivadores mais fortes da investigação que empreendemos buscando conhecer um pouco mais sobre a organização desse tão presente quanto forte movimento social de nossa história.

A questão central desta pesquisa, o processo de institucionalização da organização que Antônio Conselheiro presidiu nos sertões baianos na primeira década do período republicano, foi aqui estudada com a contraposição do discurso dos cronistas-testemunhas do episódio e a da historiografia sobre a temática com o relato oral do que ficou no imaginário dos descendentes dos sobreviventes da grande guerra da caatinga. A partir desses conteúdos procuramos revelar os traços determinantes do processo de significação dos referentes organizacionais daquela sociedade, nomeadamente de seu processo de decisão e do modelo de autoridade de seu líder, através dos elementos determinantes da dinâmica de seu sistema produtivo, ou melhor, do que dela podemos inferir.

Definitivamente, a história não é geométrica. Quaisquer que sejam a escola de pensamento ou a metodologia com as quais nos identifiquemos, o desvendar das brumas que encobrem o passado será sempre uma aventura na qual nos lançamos embalados pela paixão que nos anima e que já se esboça em nossa "carta de navegação" 
- a questão central, as hipóteses formuladas e a escolha do método. Assim, aventura maior será a de concluir, a partir da experiência dessa "viagem".

A Marc Bloch (apud DROBORUKA, 1997, p.221), um dos fundadores dos Annales, devemos a lúcida advertência, inspirada em um aforismo oriental: "os homens se parecem mais com seu tempo do que com seus pais."

Resta, portanto, resumir a singela contribuição que essas idéias encerram:

Ainda que convencidos de que a economia da sociedade do Vaza-Barris foi muito pobre, como em geral o é a de quase todo o sertão brasileiro até os nossos dias, cremos que aquele povoado desenvolveu um sistema de produção primária capaz de proporcionar o auto-abastecimento e, ainda, algum excedente, para o comércio externo, principalmente o de peles de caprinos, como fica claro nas palavras de Wolsey (Cesar Zama, médico e deputado provincial e federal baiano, 1899, p.54): "Aquella povoação proporcionava ao Estado pingue fonte de receita do imposto de exportação de pelles (sic).”

O talento administrativo e pedagógico do Bom Jesus Conselheiro e a capacidade de planejar, organizar e dirigir o seu projeto de "reinvenção do sertão" que alcançou os seguintes indicadores de desempenho:

a) execução de mais de 20 obras sociais (igrejas, cemitérios, capelas e açudes) numa área de cerca de 25 mil km2 (superior à do estado de Sergipe);

b) fundação, organização e governo de duas cidades: o arraial do Bom Jesus, atual município de Crisópolis, e o povoado do Bello Monte, situado no atual município de Canudos;

c) organização e direção, em pleno semi-árido, de um sistema produtivo capaz de abastecer uma população que experimentou, em apenas quatro anos de existência, o fantástico crescimento de 10 $335 \%$ (MARTINS, 2001); e

d) capacidade de resistência, por quase 10 meses, às investidas de ocupação militar de seu território, impostas por parte de um exército profissional (quase metade do efetivo da força terrestre brasileira de então), treinado e com superioridade de combatentes, equipamento e demais recursos.

Com base no anteriormente exposto e nos argumentos aqui desenvolvidos, propomos:

Canudos encerra um fenômeno administrativo-organizacional muito expressivo e, como tal, deve ser estudado da perspectiva de construção de uma nova disciplina: administração brasileira.

Por outro lado, a reflexão no sentido de revelar o processo de institucionalização da organização e da governança do Bello Monte aponta para as seguintes conclusões:

A sociedade das margens do rio Vaza-Barris, sob a liderança de Antônio Conselheiro, teria alcançado um razoável grau de institucionalização, a partir de um modelo de governo teocrático, de processo decisório participativo, manifestando, inclusive, em sua fase áurea, rudimentos das cinco divisões anatômicas da organização de Mintzberg (1983).

Essa sociedade parece ter conhecido, na dimensão hierárquica de sua organização de governança, os três níveis clássicos de estruturação do poder dos sistemas sociais complexos, isto é, o estratégico ou institucional, o tático ou gerencial e o operacional, e, na sua dimensão departamental, um já considerável grau de especialização/funcionalização na distribuição das tarefas de gestão da vida comunitária.

Os institutos básicos determinantes do modelo de organização da sociedade do Bello Monte e de sua forma de governo, a saber, sistema colegiado-participativo de processo decisório; embrionária estratificação do poder e da divisão do trabalho e especialização funcional; e concepção teocrática de autoridade (com conteúdo e legitimação no plano simbólico do sagrado) são aqui interpretados como resultantes da práxis do modelo produtivo mutualista - legado da tradição das três etnias básicas de formação do povo brasileiro e amplamente praticado no sertão - , da ideologia (lato sensu) de solidariedade - desenvolvida na luta do sertanejo pela sobrevivência à crônica situação de escassez da economia do semi-árido nordestino - e da fraternidade 
universal - do pensamento cristão dominante. A significação desses referentes culturais se fez, entre os seguidores do Bom Jesus, segundo os traços e estereótipos de um Estado (primeiro, imperial; depois, republicano) completamente ausente no desempenho de seu papel social e identificado, principalmente, nas figuras cínicas de seus representantes, os párocos sertanejos (da fase imperial) e os "coronéis" (das duas fases).

A leitura, assim feita, do fenômeno organizacional do governo de Canudos descodifica esse trágico e importante episódio de nossa história como um grande mutirão, cuja liderança assumiu uma forma de autoridade singular, a qual identificamos como a de um "coronel com o sinal contrário" ou de um "coronel pelo avesso", parodiando a idéia euclidiana sobre Antônio Conselheiro. 


\section{Referências}

BENICIO, Manoel. 0 rei dos jagunços: chronica histórica e de costumes sertanejos sobre os acontecimentos de Canudos. Rio de Janeiro: Typographia do Jornal do Commercio, 1899.

BLOCH, Didier (Org.). Canudos 100 anos de produção: vida cotidiana e economia dos tempos do Conselheiro até os dias atuais. Bahia: Editora Fonte Viva, 1997.

CALDEIRA, Clóvis. Mutirão: formas de ajuda mútua no meio rural. São Paulo: Companhia Editora Nacional, 1956.

CONSELHEIRO, Antônio Vicente Mendes Maciel. 0 santo evangelho de Jesus Cristo segundo São Matheus (e outros manuscritos). Bello Monte, 24 maio 1895.

Tempestades que se levantam no coração de Maria por ocasião do mistério da anunciação (e outros manuscritos). Bello Monte, 12 jan. 1897.

CUNHA, Euclydes. Os sertões (campanha de Canudos). 1.ed. Rio de Janeiro: Laemmert \& C. Editores, 1902.

Os sertões (campanha de Canudos). 31.ed. Rio de Janeiro: Francisco Alves Editora, 1982.

DOBRORUKA, Vicente. Antonio Conselheiro o beato endiabrado de Canudos. Rio de Janeiro: Diadorim, 1997.

ESPIRITO SANTO, Pedro Baptista. A pedido. Diário da Bahia, Salvador, 18 dez. 1895.

FAYOL, Henri. Administração industrial e geral. 7.ed. São Paulo: Atlas, 1968.

GOULART, Sueli; VIEIRA Marcelo Milano Falcão; CARVALHO, Cristina Amélia. Universidades e desenvolvimento local: uma abordagem institucional. Porto Alegre: Sagra Luzzatto, 2005.

LEAL, Victor Nunes. Coronelismo, enxada e voto: o município e o regime representativo no Brasil. São Paulo: Editora Alfa-Omega, 1975. LOBO, Edu; CACASO. Canudos. In: Camaleão. Rio de Janeiro: Philips, 1978. 1 LP.

MACEDO SOARES, Henrique Duque-Estrada. (tenente). A guerra de Canudos por Henrique Duque-Estrada de Macedo Soares. Rio de Janeiro: Typ. Altina, 1903.

MARTINS, Paulo Emílio Matos. A reinvenção do sertão: a estratégia organizacional de Canudos. Rio de Janeiro: Editora FGV, 2001.

MARX, Karl. Miseria de la filosofía: respuesta a la 'Filosofía de la miseria' del señor Proudhon. URSS: Editorial Progreso, 1981.

MINTZBERG, Henry. The structuring of organizations: a synthesis of the research. USA: Prentice-Hall International Editions, 1975.

Structure in fives: designing effective organizations. Englewood Cliffs: Prentice-Hall, 1983.

MONIZ, Edmundo. Canudos: a guerra social. 2.ed. Rio de Janeiro: Elo Editora, 1987.

MONTE MARCIANO, Frei João Evangelista de. Relatório apresentado, em 1895, pelo rev. Frei João Evangelista de Monte Marciano ao arcebispado da Bahia, sobre Antonio Conselheiro e seu séqüito no arraial dos Canudos. Bahia: Typographia do Correio de Noticias, 1895.

O RABUDO (Manuel Lopes de Sousa Silva, editor). 0 Rabudo, Estância, 22 nov. 1874.

OTTEN, Alexandre H. SVD. Só Deus é grande: a mensagem religiosa de Antônio Conselheiro. São Paulo: Ed. Loyola, 1990.

PETIGREW, A. M. The awakening giant: continuity and change in ICI. Oxford: Basil Blackwell, 1985.

RODRIGUEZ, Nina. As coletividades anormais. Rio de Janeiro: Civilização Brasileira, 1939.

VILLA, Marco Antonio. Canudos: o povo da terra. São Paulo: Ática, 1995. 